\title{
The use of essential oils based antiseptic solution in the treatment of denture stomatitis
}

\author{
Ognjenka Janjić-Pavlović', Ivica Stančić́, Smiljka Cicmil', Zorica Stojanović', Jelena Lečić', Sašo \\ Elenčevski ${ }^{3}$ \\ 'University od East Sarajevo, Faculty of Medicine, Dentistry Department, Foča, Bosnia and Herzegovina; \\ ${ }^{2}$ University of Belgrade, Faculty of Dental Medicine, Department of Prosthodontics, Belgrade, Serbia; \\ ${ }^{3}$ University St. Cyril and Methodius, Faculty of Dental Medicine, Department of Prosthodontics, Skopje, Macedonia
}

\begin{abstract}
SUMMARY
Introduction Local therapy of denture stomatitis (DS) associated with Candida species fungi infection usually involves the application of nystatin and miconazole. Due to the fact that these drugs may be less efficient against biofilm and possible resistance development, a new approach in the treatment includes the use of antiseptic agents.

The aim of the study was to compare clinical and microbiological therapeutic outcomes of antiseptic solution Listerine ${ }^{\circ}$ and Daktanol ${ }^{\circ}$ antifungal oral gel in the treatment of DS associated with Candida species fungi.

Material and Methods The study included 30 patients affected by DS, divided into the two treatment groups, control group $(n=15)$ treated by Daktanol ${ }^{\circ}$ gel and experimental group $(n=15)$ treated by the antiseptic solution Listerine ${ }^{\circ}$. Successful treatment was evaluated based on palatal mucosa inflammation reduction classified according to the Newton classification and the difference in the number of fungal colony- forming units (CFU) isolated by smears before and after the treatment that lasted 14 days.

Results Reduction in inflammation intensity and fungal CFU number on palatal mucosa $(p<0,01)$ as well as on denture base $(p<0,01)$ were observed in both groups of subjects after the treatment.

Conclusion Antiseptic solution Listerine ${ }^{\circ}$ and Daktanol ${ }^{\circ}$ antifungal gel both reduced palatal mucosal inflammation and CFU number of fungi in mouth without significant differences among them. CFU number of fungi isolated from denture base was significantly lower after the treatment with Listerine ${ }^{\circ}(\mathrm{p}<0.05)$.

Keywords: Candida albicans; denture stomatitis; Listerine, Daktanol gel
\end{abstract}

\section{INTRODUCTION}

Denture stomatitis (DS) is an inflammation of oral mucosa covered by the denture base with reported incidence of $15-70 \%$ [1]. It is linked to a number of non-infectious aetiologies such as poor quality of dentures, poor hygiene and nocturnal denture wearing as well as infectious etiological factor, Candida species fungi [2]. Number of fungal cells in the saliva and on dentures is leading etiological factor for DS development [3]. The degree of Candida albicans (C.albicans) denture base contamination is directly correlated to inflammation intensity [4].

This disease is characterized by erythema of oral mucosa covered by the denture base; it is usually asymptomatic and often associated with angular cheilitis [5]. Its intensity is clinically evaluated according to the Newton classification criteria [6,7]. DS treatment most frequently includes local and systemic administration of antifungals, reduction and eradication of biofilm, change of bad habits related to nocturnal denture wearing and poor denture hygiene as well as replacement of inadequate dentures. The most frequently used local antifungal drugs in dental practice are nystatin and miconazole [8,9]. Although effectively act against fungi, these drugs have no effect on biofilm matrix, therefore well-protected pathogens can survive in extracellular matrix. Also, their use comes with the risk of resistance development $[10,11]$. Commercially available oral antiseptic Listerine ${ }^{\oplus}$ acts directly against fungal cell, chemically, causing damage to the cell wall structure and membrane permeability. Also, it disrupts metabolic processes dependant on microorganism membrane enzymes, and, as other phenolic products, exerts anti-inflammatory effect [12]. Listerine ${ }^{\oplus}$ acts against free unbound Candida cells as well as against formed biofilm and it is shown to be more efficient than the azole antifungal drugs [13]. This Listerine ${ }^{\circledast}$ solution property has not been studied in a clinical trial yet.

The aim of this study was to compare clinical and microbiological outcomes of antiseptic agent Listerine ${ }^{\oplus}$ and antifungal Daktanol ${ }^{\top}$ gel in the treatment of DS associated with Candida species fungi.

\section{MATERIAL AND METHODS}

This prospective clinical study was conducted at the Department of Dental Medicine in Foca and the Microbiological laboratory of the University Hospital Foca. The 
research was conducted in accordance with the principles of the Helsinki Declaration of 2008. Prior to inclusion in the study subjects were informed about the aim and the protocol of research and gave their consent to participation. The study included 30 patients, maxillary acrylic dentures wearers, affected by DS. Criteria for inclusion of patients in the study were good general health, or chronic well-controlled disease and dental acrylic dentures wearing for at least one year. Also, swabs of palatal mucosa and denture basal surface had to be positive on Candida species fungi. Exclusion criteria were as follows: the use of corticosteroids and immunosuppressive therapy, tumours of the maxillofacial region and radiotherapy in the head and neck area, chemotherapy in the last year, blood disorders, local surgical therapy in the last 3 months, local or systemic use of antibiotics and antifungal drugs in the last 3 months, the use of hormones for therapeutic purposes, the existence of other diseases in the oral cavity and also functionally, prophylactically and cosmetically inadequate dentures that are indicated for replacement with new dentures.

By the means of random numbers table, participants who joined the study under even-number were classified into the control group and received standard treatment with Daktanol $^{\circ}$ oral gel (2\% miconazole, Galenika a.d. Belgrade, Serbia). The participants included in the study under odd-number were classified into the experimental group and were treated with antiseptic agent Listerine ${ }^{\circ}$ cool mint ${ }^{\mathrm{TM}}$ (Johnson\&Johnson, S.p.A. Rome, Italy). Each group consisted of 15 patients, and therapy was administered according to the following protocol:

1. Control group of patients $(n=15)$ received standard local antifungal therapy in the form of Daktanol $^{\circ}$ gel containing 2\% miconazole, used at the dose of 1-2 teaspoons, 4 times per day for 14 days. Basal surface of dentures were coated with gel overnight and rinsed with water in the morning prior to use.

2. Experimental group of patients $(n=15)$ used an antiseptic agent Listerine ${ }^{\circledast}$ also for 14 days as follows: 4 times a day 1 minute long mouth swish with antiseptic solution that was spitted afterward. Dentures were immersed in this solution overnight with base facing upward in a glass container, and completely overflowed by the Listerine ${ }^{\oplus}$ solution. In the morning dentures were rinsed with water.

Parameters used for the evaluation of inflammation and denture contamination, as well as the presence of expected improvement were clinical and microbiological. Clinical improvement implied palatal mucosa inflammation intensity reduction after the treatment compared to the inflammation intensity prior to the therapy.

\section{Clinical parameters}

The intensity of palatal mucosa inflammation was assessed by Newton classification which distinguishes three clinical types of denture stomatitis [6,7]: type Newton I: dotted hyperaemic shape and size of a pinhead lesion (pin-point) that present localized areas of poorly expressed inflammation; type Newton II: diffuse erythema of palatal mucosa covered by the denture base - general- ized inflammation; type Newton III: granular surface of the mucosa- inflammatory papillary hyperplasia.

\section{Microbiological parameters}

Swabs of palatal mucosa surfaces and denture bases were taken without prior mouth and dentures rinsing, in the morning, before any food intake. Sabouraud dextrose agar was used to grow fungi and it was incubated at 37 ${ }^{\circ} \mathrm{C}$, for 48 hours. The number of fungal colonies (CFUcolony forming units) was counted after 48 hours. The following criteria were used for CFU quantification: $<10$ colonies present after incubation - smear is negative; 10 25 colonies present after incubation - fungi present in small numbers; $>25$ colonies present after incubation fungi are present in large numbers [14]. Two days after the treatments, control examinations were conducted and swabs for samples cultivation were taken again.

The obtained data were statistically analyzed in the SPSS software (SPSS for Windows, version 11.5, Chicago, Ill.). Description of the sample was carried out by descriptive statistics methods. Therapeutic results within a group (paired samples) were evaluated by the Wilcoxon Signed Rank test. The effect of the therapy on the clinical improvement was assessed using the Fisher's Exact Test, and therapeutic results between observed groups were compared using $\chi^{2}$ test. The relationship between certain characteristics and inflammation intensity as well as therapy outcomes were estimated using $\chi^{2}$ test and Fisher's Exact Test. Results are presented in tables.

\section{RESULTS}

The study included 30 patients, 19 (63.3\%) female and $11(36.7 \%)$ male, with an average age of 56.1 years $(\mathrm{SD}=$ 7.126). The largest number of dentures, 17 (56.7\%), was between 5 and 10 years old, 9 dentures (30\%) were aged over 10 years, while 4 dentures $(13.3 \%)$ were used less than 5 years. Most of patients, 27 (90\%) had clinically present denture stomatitis classified as type II Newton, while 3 patients (10\%) had denture stomatitis Newton type III.

In both groups, significant reduction in the CFU number at the palate $(\mathrm{p}<0.01)$ as well as at the denture base was observed after the treatments $(\mathrm{p}<0.01)$ (Table 1$)$.

Inflammation intensity reduction was observed in most patients, but significant difference after treatments between the two applied therapeutic modalities was not observed (Table 2). There was no significant difference in palate smear CFU number reduction in relation to the applied therapy, but significant difference $(\mathrm{p}<0.05)$ was observed in denture smear CFU number reduction in patients treated with antiseptic agent Listerine ${ }^{\oplus}$ compared to patients treated by Daktanol ${ }^{\circ}$ oral gel (Table 3).

Gender, age of patients or age of dentures, had no statistically significant effect on clinical improvement after the treatment, as well as on the reduction in the CFU numbers isolated from palatal mucosa and denture basal surface after the treatment (Table 4) 
Table 1. Reduction of isolated fungal colony forming unit (CFU) number after the treatment

Tabela 1. Smanjenje broja izolovanih gljivičnih kolonija nakon završene terapije

\begin{tabular}{|l|c|c|c|c|}
\hline \multirow{2}{*}{$\begin{array}{l}\text { CFU number before and } \\
\text { after the treatment } \\
\text { Broj CFU pre i posle } \\
\text { terapije }\end{array}$} & \multicolumn{2}{|c|}{ Listerine $^{\circ}$} & \multicolumn{2}{c|}{ Daktano $^{\circ}$} \\
\cline { 2 - 5 } & Nepce & $\begin{array}{c}\text { Denture } \\
\text { base } \\
\text { Proteza }\end{array}$ & $\begin{array}{c}\text { Palate } \\
\text { Nepce }\end{array}$ & $\begin{array}{c}\text { Denture } \\
\text { base } \\
\text { Proteza }\end{array}$ \\
\hline $\begin{array}{l}\text { Increased CFU number } \\
\text { Povećan broj CFU }\end{array}$ & 0 & 0 & 0 & 0 \\
\hline $\begin{array}{l}\text { Decreased CFU number } \\
\text { Smanjen broj CFU }\end{array}$ & 15 & 15 & 14 & 15 \\
\hline $\begin{array}{l}\text { Unchanged CFU } \\
\text { Nepromenjen CFU }\end{array}$ & 0 & 0 & 1 & 0 \\
\hline Z; p & $-3.542 ;$ & $-3.397 ;$ & $-3.520 ;$ & $-3.508 ;$ \\
0.000 & 0.001 & 0.000 & 0.000 \\
\hline
\end{tabular}

Paired sample, Wilcoxon Signed Rank test

Vezani uzorak, Vilkoksonov test ekvivalentnih parova

Table 2. The influence of applied treatments on the clinical improvement

Tabela 2. Efikasnost primenjenog tretmana na kliničko poboljšanje

\begin{tabular}{|l|c|c|c|}
\hline \multirow{2}{*}{$\begin{array}{l}\text { Clinical improvement } \\
\text { Kliničko poboljšanje }\end{array}$} & \multicolumn{2}{|c|}{ Applied therapy } & \multirow{2}{*}{$\begin{array}{c}\text { Total } \\
\text { Ukupno } \\
\text { (n; \%) }\end{array}$} \\
\cline { 2 - 3 } & Daktanol $^{\odot}$ & Listerine & 24;80.0 \\
\hline $\begin{array}{l}\text { Yes } \\
\text { Da }\end{array}$ & $11 ; 60.0$ & $13 ; 86.7$ & 6; 20.0 \\
\hline $\begin{array}{l}\text { No } \\
\text { Ne }\end{array}$ & $4 ; 40.0$ & $2 ; 13.3$ & 20 \\
\hline $\begin{array}{l}\text { Total } \\
\text { Ukupno }\end{array}$ & $15 ; 100.0$ & $15 ; 100.0$ & $30 ; 100.0$ \\
\hline
\end{tabular}

Fisher's Exact Test $=0.241$

Fišerov test tačne verovatnoće $=0,241$

Table 3. Reduction of fungal colonies number isolated from palate and denture base after the treatment

Tabela 3. Efikasnost primenjenih terapija na smanjenje broja gljivičnih kolonija izolovanih sa nepca i baze proteze nakon terapije

\begin{tabular}{|c|c|c|c|c|}
\hline \multirow{2}{*}{\multicolumn{2}{|c|}{$\begin{array}{l}\text { Reduction of the number of } \\
\text { fungal colonies } \\
\text { Smanjenje broja gljivičnih } \\
\text { kolonija }\end{array}$}} & \multicolumn{2}{|c|}{$\begin{array}{l}\text { Applied treatment } \\
\text { Primenjena terapija }\end{array}$} & \multirow{3}{*}{$\begin{array}{c}\begin{array}{c}\text { Total } \\
\text { Ukupno } \\
(\mathbf{n} ; \%)\end{array} \\
21 ; 70.0 \%\end{array}$} \\
\hline & & Daktanol $^{\oplus}$ & Listerine $^{\bullet}$ & \\
\hline \multirow{3}{*}{$\begin{array}{l}\text { Palate* } \\
\text { Nepce }^{*}\end{array}$} & $\begin{array}{l}\text { Yes } \\
\mathrm{Da}\end{array}$ & $9 ; 60.0 \%$ & $12 ; 80.0 \%$ & \\
\hline & $\begin{array}{l}\text { Partially } \\
\text { Delimično }\end{array}$ & $5 ; 33.3 \%$ & $3 ; 20.0 \%$ & $8 ; 26.7 \%$ \\
\hline & $\begin{array}{l}\mathrm{No} \\
\mathrm{Ne}\end{array}$ & $1 ; 6.7 \%$ & $0 ; 0.0 \%$ & $1 ; 33 \%$ \\
\hline \multirow{3}{*}{$\begin{array}{l}\text { Denture base } e^{* *} \\
\text { Baza proteze }\end{array}$} & $\begin{array}{l}\text { Yes } \\
\mathrm{Da}\end{array}$ & $8 ; 53.3 \%$ & $14 ; 93.3 \%$ & $22 ; 73.3 \%$ \\
\hline & $\begin{array}{l}\text { Partially } \\
\text { Delimično }\end{array}$ & $7 ; 46.7 \%$ & $1 ; 6.7 \%$ & $8 ; 26.7 \%$ \\
\hline & $\begin{array}{l}\mathrm{No} \\
\mathrm{Ne}\end{array}$ & $0 ; 0.0 \%$ & $0 ; 0.0 \%$ & $0 ; 0.0 \%$ \\
\hline
\end{tabular}

${ }^{*} \chi^{2}=1.929 ; \mathrm{df}=2 ; \mathrm{p}=0.381$

${ }^{* *} \chi^{2}=6.136 ; \mathrm{df}=1 ; \mathrm{p}=0.013$

\section{DISCUSSION}

The present study evaluated the effect of oral antiseptic Listerine ${ }^{\varpi}$ on palatal mucosa inflammation and Candida species CFU number isolated from palatal mucosa and denture base among denture wearers affected with DS.

Literature review couldn't identify other similar clinical studies. Yet, there are indirect evidences of Listerine ${ }^{\varpi}$ antifungal properties that justify its use in DS treatment. Meiller et al. conducted an in vitro study in which they observed the effect of Listerine ${ }^{\otimes}$ on clinically isolated Candida species, British and American strains of the same species. Fungal cells were incorporated into an experimental biofilm. Authors reported that after 60 seconds of experimental biofilm exposure to this antiseptic, no living fungal cells were observed in the sample [15]. In a study conducted with clinically isolated Candida species, Listerine ${ }^{\varpi}$ showed very good antimicrobial activity in laboratory testing. After 60 minutes, there was no living cell of Candida species in the sample [16]. Listerine ${ }^{\circledast}$ was also efficient against experimental biofilm composed of one laboratory and 34 clinically isolated $C$. albicans strains where it reduced metabolical activity of fungi for $75-80 \%$ [13]. The effect of Listerine ${ }^{\oplus}$ against C.albicans clinical isolates was confirmed in a recent study where Listerine ${ }^{\oplus}$ reduced C.albicans growth on Sabouraud dextrose agar [17]. The results presented in this study clinically confirmed findings of previous in vitro studies.

In the present study, Listerine ${ }^{\circledast}$ showed better efficacy in reducing the number of $\mathrm{CFU}$ isolated from denture basis compared to the Daktanol $^{\circ}$ gel. This finding could be the result of different viscosity of used agents. Miconazole was applied in a form of gel, what might hinder its denture base coating. However, due to its physical caracteristics, Listerine ${ }^{\oplus}$ solution, could reach rugged, porous acrylic surface more easily. Beside therapy, improved hygiene and avoiding nocturnal dentures wearing could have positive impact on palatal mucosa inflammation reduction.

\section{CONCLUSION}

Therapeutic outcomes after the use of antiseptic agent Listerine ${ }^{\circledast}$ in DS treatment are similar to the therapeutic outcomes obtained by standard Daktanol ${ }^{\circ}$ oral gel therapy. Therefore, Listerine ${ }^{\odot}$ can be used in the treatment of DS associated with Candida species.

Table 4. Influence of gender, age of respondents and age of dentures on the treatment outcome

Tabela 4. Uticaj pola, starosti ispitanika i starosti proteza na ishod terapije

\begin{tabular}{|l|c|c|c|}
\hline & $\begin{array}{c}\text { Clinical improvement } \\
\text { Kliničko poboljšanje }\end{array}$ & $\begin{array}{c}\text { Reduction of CFU in palate smear } \\
\text { Smanjenje CFU izolovanih u brisu nepca }\end{array}$ & $\begin{array}{c}\text { Reduction of CFU in denture base smear } \\
\text { Smanjenje CFU izolovanih u brisu proteza }\end{array}$ \\
\hline Gender & Fisher's Exact Test & $\chi^{2}=0.600$ & $\chi^{2}=0.695$ \\
$\mathrm{p}=0.706$
\end{tabular}




\section{REFERENCES}

1. Gendreau L, Loewy ZG. Epidemiology and aetiology of denture stomatitis. J Prosthodont. 2011; 20(4):251-60. [DOI: 10.1111/j.1532-849X.2011.00698.x] [PMID: 21463383]

2. Thein Z, Samaranayake Y, Samaranayake L. Characteristis of dual species Candida biofilms on denture acrylic surfaces. Arch Oral Bio. 2007; 52(12):1200-08. [DOl: 10.1016/j.archoralbio.2007.06.007] [PMID: 17681271]

3. Altarawneh S, Bencharit S, Mendoza L, Curran A, Barrow D, Barros $S$, et al. Clinical and histological findings of denture stomatitis as related to intraoral colonization patterns of Candida albicans, salivary flow and dry mouth. J Prosthodont. 2013; 22(1):13-22. [DOI: 10.1111/j.1532-849X.2012.00906.x] [PMID: 23107189]

4. Naik AV, Pai RC. A study of factors contributing to Denture stomatits in a North Indian community. Int J Dent. 2011; 2011:589064. [DOI: 10.1155/2011/589064] [PMID: 22194746]

5. Martori E, Ayuso-Montero R, Martinez-Gomis J, Viñas M, Peraire M. Risk factors for denture-related oral mucosal lesions in a geriatric population. J Prosthet Dent. 2014; 111:273-9.

[DOI: 10.1016/j.prosdent.2013.07.015] [PMID: 24355508]

6. Newton AV. Denture sore mouth. Br Dent J. 1962; 112:357-60

7. Yarborough A, Cooper L, Duqum I, Mendoca G, McGraw K, Stoner L. Evidence regarding the treatment of denture stomatitis. J Prosthodont. 2016; 25(4):288-301. [DOI: 10.1111/jopr.12454] [PMID: 27062660]

8. Oliver RJ, Dhaliwal HS, Theaker ED, Pemberton MN. Patterns of antifungal prescribing in general dental practice. Br Dent J. 2004; 196:701-3. [DOI: 10.1038/sj.bdj.4811354] [PMID: 15192736 ]

9. Martínez-Beneyto Y, López-Jornet P, Velandrino-Nicolás A, JornetGarcía V. Use of antifungal agents for oral candidiasis: results of a national survey. Int I Dent Hyg. 2010; 8:47-52

[DOI: 10.1111/j.1601-5037.2008.00357.x] [PMID: 20096082]

10. Uzunović-Kamberović SU. Medicinska mikrobiologija. Zenica: Štamparija Fojnica; 2009; 612-20.

11. Niimi M, Firth NA, Cannon RD. Antifungal drug resistance of oral fungi. Odontology. 2010; 98(1):15-25.

[DOI: 10.1007/s10266-009-0118-3] [PMID: 20155503]

12. Seymour RA, Meechan JG, Yates MS. Antimicrobial chemotherapy In: Pharmacology and dental therapeutics. 3rd ed. Oxford University Press. 1999. pp. 150-76

13. Ramage G, Jose A, Coco B, Rajendran R, Rautemaa R, Murray C, et al. Commercial mouthwashes are more effective than azole antifungals against C.albicans biofilms in vitro. Oral Surg Oral Med Oral Pathol Oral Radiol Endod. 2011; 111:456-60. [DOI: 10.1016/j.tripleo.2010.10.043] [PMID: 21310633]

14. Budtz-Jorgensen E. The significance of Candida albicans in denture stomatitis. Scand I Dent Res. 1974; 82:151-90. [PMID: 4598186]

15. Meiller TF, Kelley Jl, Jabra-Risk MA, DePaola LG, Baqui AAMA, Falkler WA. In vitro studies of the efficacy of antimicrobials against fungi. Oral Surg Oral Med Oral Pathol Oral Radiol Endod. 2001; 91(6):663-70. [DOl: 10.1067/moe.2001.113550]

16. Shrestha A, Rimal J, Rao A, Sequeira PS, Doshi D, Bhat GK. In vitro antifungal effect of mouth rinses containing chlorhexidine and thymol. J Dent Sci. 2011; 6:1-5. [DOI: 10.1016/j.jds.2011.02.001]

17. Fu J, Wei P, Zhao C, He C, Yan Z, Hua H. In vitro antifungal effect and inhibitory activity on biofilm formation of seven commercial mouthwashes. Oral Dis. 2014; 20(8):815-20. [DOI: 10.1111/odi.12242] [PMID: 24724892]

Received: 26.12.2016 • Accepted: 22.02.2017 


\title{
Primena antiseptičnog sredstva na bazi esencijalnih ulja u terapiji proteznog stomatitisa
}

\author{
Ognjenka Janjić-Pavlović1, Ivica Stančić ${ }^{2}$ Smiljka Cicmil', Zorica Stojanović1, Jelena Lečić1, Sašo Elenčevski \\ 'Univerzitet u Istočnom Sarajevu, Medicinski fakultet, Katedra za oralnu rehabilitaciju, studijski program Stomatologija, Foča, Bosna i \\ Hercegovina; \\ Univerzitet u Beogradu, Stomatološki fakultet, Klinika za stomatološku protetiku, Beograd, Srbija; \\ ${ }^{3}$ Univerzitet sv. Kiril i Metodije, Stomatološki fakultet, Katedra za stomatološku protetiku, Skoplje, Makedonija
}

\begin{abstract}
KRATAK SADRŽAJ
Uvod Lokalna terapija proteznog stomatitisa (PS) udruženog sa infekcijom gljivicama iz roda Candida najčešće se sprovodi upotrebom nistatina i mikonazola. Zbog otežanog dejstva ovih lekova na biofilm, kao i zbog razvoja moguće rezistencije, pažnja se usmerava na terapijske efekte koji se mogu postići primenom antiseptičkih sredstava.

Cilj rada je da se uporede klinički i mikrobiološki ishodi primene antiseptičkog rastvora Listerine ${ }^{\bullet}$ i oralnog gela sa antimikotskim dejstvom Daktanol ${ }^{\circ}$ u lečenju PS udruženog sa pojavom gljivica iz roda Candida.

Metode rada Studija je uključivala 30 ispitanika obolelih od PS, podeljenih u dve terapijske grupe: kontrolnu $(n=15)$ lečenu gelom Daktanol $^{\circ}$ i eksperimentalnu $(n=15)$ - antiseptikom Listerine ${ }^{\circ}$. Uspešnost terapije procenjivana je na osnovu smanjenja intenziteta zapaljenja palatinalne sluzokože procenjenog prema klasifikaciji Newton pre početka lečenja i razlike u broju brisom izolovanih gljivičnih kolonija (CFU) pre i posle terapije, koja je trajala 14 dana.

Rezultati Kod obe grupe ispitanika došlo je do smanjenja intenziteta zapaljenja i smanjenja CFU i na nepcu $(p<0,01)$ i na bazi proteze $(\mathrm{p}<0,01)$ nakon terapije.

Zaključak Antiseptički rastvor Listerine ${ }^{\circ}$ i antimikotik Daktanol ${ }^{\circ}$ dovode do smanjenja intenziteta zapaljenja palatinalne sluzokože i do značajnog smanjenja CFU u terapiji PS, bez međusobno značajne razlike, osim u smanjenju broja CFU izolovanih sa baze proteza nakon terapije, gde je rastvor Listerine ${ }^{\circ}$ pokazao veću efikasnost $(p<0,05)$.

Ključne reči: Candida albicans; protezni stomatitis; Listerine, Daktanol gel
\end{abstract}

\section{UVOD}

Protezni stomatitis (PS) jeste zapaljenje oralne sluzokože pokrivene bazom proteze sa prijavljenom učestalošću od 15 do $70 \%$ [1]. Povezan je sa brojnim neinfektivnim etiološkim faktorima kao što su loš kvalitet proteza, slaba higijena i noćno nošenje nadoknada, kao i sa infektivnim etiološkim faktorom, gljivicama iz roda Candida [2]. Broj gljivičnih ćelija u pljuvački i na samim protezama igra vodeću ulogu u razvoju PS [3]. Stepen kontaminacije baze proteze gljivicom Candida albicans (C. albicans) u direktnoj je korelaciji sa intenzitetom zapaljenja palatinalne sluzokože [4].

Oboljenje karakteriše eritem onih područja oralne sluzokože koja su pokrivena bazom proteze, često je udruženo sa angularnim heilitisom i najčešće je asimptomatsko [5]. Intenzitet oboljenja se klinički procenjuje klasifikacijom Newton [6, 7]. Terapija najčešće obuhvata lokalnu i sistemsku primenu antimikotika, redukciju i eradikaciju biofilma, promenu loših navika vezanih za noćno nošenje i slabu higijenu proteza, te zamenu postojećih proteza ukoliko su neadekvatne. Dva najčešće primenjivana lokalna antimikotika u stomatološkoj praksi su nistatin i mikonazol $[8,9]$. Iako efikasno deluju na gljivice, ovi lekovi nemaju uticaj na sam matriks biofilma, te dobro zaštićeni patogeni u ekstracelularnom matriksu mogu preživeti, a moguć je i razvoj rezistencije $[10,11]$. Komercijalno dostupan oralni antiseptik Listerine ${ }^{\circledast}$ na gljivičnu ćeliju deluje direktno, hemijski, dovodeći do oštećenja strukture ćelijskog zida i poremećaja kontrole permeabiliteta membrane. Takođe, prekida metaboličke procese koji zavise od enzima prisutnih u membrani mikroorganizma, te kao i ostali fenolni preparati ispoljava antiinflamatorno dejstvo [12]. Listerine ${ }^{\circledast}$ deluje i na slobodne nevezane ćelije Candide, kao i na formirani biofilm i to sa većom efikasnošću od azolnih antimikotika [13]. Ova dejstva rastvora Listerine ${ }^{\circledast}$ do sada nisu ispitivana u kliničkim uslovima.

Cilj rada bio je da se uporede klinički i mikrobiološki ishodi primene antiseptičkog sredstva Listerine ${ }^{\circledast}$ i antimikotika Daktanol $^{\varpi}$ u lečenju PS udruženog sa pojavom gljivica iz roda Candida.

\section{MATERIJAL I METODE RADA}

Ova prospektivna klinička studija sprovedena je na Klinici za stomatologiju Medicinskog fakulteta u Foči i u Mikrobiološkoj laboratoriji Univerzitetske bolnice Foča. Istraživanje je sprovedeno u skladu sa principima Helsinške deklaracije iz 2008. godine, a pre uključivanja u studiju ispitanici su bili upoznati sa ciljem i protokolom istraživanja i dali svoju saglasnost za učestvovanje $\mathrm{u}$ istom. Studija je obuhvatala 30 ispitanika, nosilaca gornjih totalnih akrilatnih proteza, obolelih od proteznog stomatitisa. Kriterijumi za uključivanje ispitanika u studiju bili su dobro opšte zdravstveno stanje, odnosno dobro kontrolisano opšte oboljenje i nošenje totalne proteze bar jednu godinu. Takođe, brisevi palatinalne sluzokože i bazalne površine proteze morali su biti pozitivni na gljivice iz roda Candida. Kriterijumi za isključenje bili su sledeći: upotreba kortikosteroida i imunosupresivna terapija, tumori maksilofacijalne regije, zračna terapija u predelu glave i vrata, primenjena hemoterapija u poslednjoj godini dana, krvne diskrazije, lokalna hirurška terapija u protekla tri meseca, lokalna ili sistemska upotreba antibiotika i antimikotika u poslednja tri meseca, upotreba hormona u terapijske svrhe, postojanje drugog oboljenja u usnoj duplji, te neadekvatne proteze čija je funkcionalna, profilaktička i estetska vrednost ugrožena u tolikoj meri da je indikovana izrada novih nadoknada. 
Pomoću tablice slučajnih brojeva određeno je da se ispitanici koji su se u studiju priključili pod parnim rednim brojem svrstaju u kontrolnu grupu i primaju standardnu terapiju oralnim gelom Daktanol $^{\oplus}$ (2\% mikonazol, Galenika a.d. Beograd, Srbija). Ispitanici uključeni u studiju pod neparnim rednim brojem svrstani su u eksperimentalnu grupu i primili su terapiju antiseptičnim sredstvom Listerine ${ }^{\circledast}$ cool mint ${ }^{T M}$ (Johnson \& Johnson, S.p.A. Rim, Italija). Svaka grupa se sastojala od po 15 ispitanika, a terapija je primenjivana po sledećem protokolu:

1. kontrolna grupa ispitanika $(n=15)$ primala je standardnu lokalnu antifungalnu terapiju u vidu gela Daktanol ${ }^{\oplus}$, koji sadrži $2 \%$ mikonazola, u dozi od 1-2 kafene kašičice, četiri puta dnevno, tokom 14 dana. Proteze su se preko noći sa bazalne strane premazivale gelom, a ujutro ispirale vodom pre upotrebe.

2. eksperimentalna grupa ispitanika $(n=15)$ koristila je antiseptično sredstvo Listerine ${ }^{\circledast}$ i to po sledećem režimu: četiri puta dnevno jednominutno mućkanje antiseptičnog rastvora, koji se nakon tog vremena ispljune, a proteze su preko noći potapali u ovaj rastvor tako što su ih postavljali u čašu, bazom okrenutom ka gore i prelivali rastvorom Listerine ${ }^{\varpi}$ do potpunog prekrivanja svih njenih površina. Ujutro su se proteze ispirale vodom, a terapija je takođe trajala 14 dana.

Parametri na osnovu kojih se procenjivao stepen inflamacije i kontaminacije nadoknada, kao i nastupanje očekivanog poboljšanja, bili su klinički i mikrobiološki. Kliničko poboljšanje podrazumevalo je smanjenje intenziteta zapaljenja sluzokože nakon terapije u odnosu na intenzitet utvrđen pre terapije.

\section{Klinički parametri}

Intenzitet zapaljenja palatinalne sluzokože procenjivao se klasifikacijom Newton, prema kojoj razlikujemo tri klinička tipa proteznog stomatitisa [6, 7]: tip Newton I - tačkaste hiperemične lezije oblika i veličine glave čiode koje predstavljaju lokalizovana područja slabo izraženog zapaljenja; tip Newton II - difuzni eritem cele nepčane sluznice koja je pokrivena bazom proteze - generalizovano zapaljenje; te tip Newton III - granularna površina mukoze - zapaljenska papilarna hiperplazija.

\section{Mikrobiološki parametri}

Uzimanje brisa inflamatorno promenjene nepčane sluzokože i bazne površine proteze vršeno je ujutro, natašte, bez prethodnog ispiranja usne šupljine i proteza, sterilnim štapićem vate. Materijal se zasijavao na saburo dekstrozni agar i inkubirao na $37^{\circ} \mathrm{C}$, 48 časova, nakon čega su utvrđivani prisustvo i broj gljivičnih kolonija. Da bi se kvantifikovao broj gljivičnih kolonija (CFU - colonie forming units), korišćeni su sledeći kriterijumi: <10 kolonija nakon inkubacije - bris je negativan; 10-25 kolonija prisutnih nakon inkubacije - gljivice prisutne u manjem broju i $>25$ kolonija prisutnih nakon inkubacije - gljivice prisutne u većem broju [14]. Dva dana nakon isteka terapije vršeni su kontrolni pregledi i ponovo su uzimani brisevi za kultivaciju uzoraka.

Dobijeni podaci su statistički obrađeni u SPSS programu (SPSS za Windows, verzija 11.5, Chicago, Ill.). Opis uzorka vršen je metodama deskriptivne statistike. Terapijski rezultati unutar jedne grupe (vezani uzorak) procenjeni su pomoću Vilkoksonovog testa ekvivalentnih parova. Uticaj terapije na kliničko poboljšanje procenjen je primenom Fišerovog testa tačne verovatnoće, a terapijski rezultati između ispitivanih grupa poređeni su pomoću $\chi^{2}$ testa. Povezanost pojedinih obeležja sa intenzitetom zapaljenja i ishodom terapije procenjen je pomoću $\chi^{2}$ testa i Fišerovog testa tačne verovatnoće. Rezultati su prikazani tabelarno.

\section{REZULTATI}

U studiju je bilo uključeno 30 ispitanika, 19 (63,3\%) ženskog i $11(36,7 \%)$ muškog pola, prosečne starosti 56,1 godina (SD $=7,126)$. Najveći broj proteza $-17(56,7 \%)$ bio je star između pet i deset godina, devet proteza (30\%) bile su stare više od deset godina, dok su četiri proteze $(13,3 \%)$ korišćene kraće od pet godina. Najveći broj pacijenata - 27 (90\%) imao je klinički izražen protezni stomatitis klasifikovan kao tip Newton II, dok su tri pacijenta (10\%) imala protezni stomatitis tipa Newton III.

Kod obe grupe ispitanika došlo je do visoko značajnog smanjenja broja CFU i na nepcu $(\mathrm{p}<0,01)$ i na bazi proteze nakon terapije $(\mathrm{p}<0,01)$ (Tabela 1$)$.

Smanjenje intenziteta zapaljenja nastupilo je kod većine ispitanika, bez uočenog postojanja značajne razlike nakon terapije između dva primenjena terapijska modaliteta (Tabela 2). Nije pronađena značajna razlika u smanjenju broja CFU dobijenih brisom nepca u odnosu na primenjenu terapiju, ali je nađena značajna razlika $(\mathrm{p}<0,05)$ u smanjenju broja CFU izolovanih brisom baze proteze kod pacijenata lečenih antiseptičnim sredstvom Listerine ${ }^{\circledast} \mathrm{u}$ odnosu na pacijente lečene oralnim gelom Daktanol $^{\oplus}$ (Tabela 3).

Pol i starost pacijenata, kao ni starost proteza, nisu imali statistički značajnog uticaja na smanjenje intenziteta zapaljenja nakon terapije, kao ni na smanjenje CFU broja izolovanih sa palatinalne sluzokože i bazalnih površina proteza nakon terapije (Tabela 4).

\section{DISKUSIJA}

U našoj studiji procenjivan je uticaj oralnog antiseptika Listeri$n e^{\circledast}$ na stepen inflamacije palatinalne sluzokože i broj kolonija gljivica iz roda Candida na nepcu i proteznoj ploči kod nosilaca totalnih proteza obolelih od proteznog stomatitisa.

Druge kliničke studije koje su koristile isti tretman, po istom ili sličnom protokolu kao u našem istraživanju, nisu nađene pregledom literature. Ipak, postoje posredni dokazi o antifungalnom dejstvu ovog sredstva koji opravdavaju njegovu primenu u terapiji proteznog stomatitisa. Meiller i saradnici su sproveli in vitro studiju u kojoj je proučavano dejstvo antiseptika Listerine ${ }^{\circledast}$ na kliničke izolate iz roda Candida i britanske i američke laboratorijske sojeve istog roda. Posmatrajući antimikrobno dejstvo na gljivične ćelije u sastavu eksperimentalnog biofilma, utvrđeno je da nakon 60 sekundi izlaganja ovom antiseptiku više nije bilo živih gljivičnih ćelija u uzorku [15]. U studiji u kojoj su uzorci mikroorganizama poticali od pacijenata sa Candidapozitivnim brisom oralne sluzokože, Listerine ${ }^{\circledast}$ je pokazao veoma dobru antimikrobnu aktivnost $\mathrm{u}$ in vitro uslovima. Nakon 60-minutnog izlaganja, u uzorku nije bilo živih ćelija C. albicans [16]. U studiji u kojoj je ispitivano dejstvo antiseptika Listerine ${ }^{\circledast}$ na biofilm sastavljen od jednog laboratorijskog i 34 klinički izolovana soja vrste C. albicans, utvrđeno je da je Listerine ${ }^{\circledast}$ re- 
dukovao postojeću metaboličku aktivnost gljivica za 75-80\% [13]. Efekat sredstva Listerine ${ }^{\circledast}$ na kliničke izolate C. albicans u biofilmu laboratorijski je potvrđen i u skorijem istraživanju, gde je Listerine ${ }^{\circledast}$ inhibisao rast C. albicans na saburo agaru [17]. Rezultati prikazani u našem istraživanju klinički su potvrdili nalaze navedenih in vitro studija, što se ogleda u smanjenju broja brisom izolovanih gljivičnih kolonija sa nepca i baze proteza nakon terapije proteznog stomatitisa.

Listerine $^{\circledast}$ je u našoj studiji pokazao veću efikasnost u smanjenju broja gljivičnih kolonija izolovanih brisom baze proteze $\mathrm{u}$ odnosu na rezultat dobijen u kontrolnoj grupi. Na ovakav nalaz je mogla uticati različita viskoznost primenjenih sredstava. Mikonazol je bio primenjen u formi gela, pa je samim tim teže oblagao površinu proteza. Listerine ${ }^{\circledast}$ je zbog fizičkih karakteristika rastvora lakše dopirao do neravnih, poroznih prostora $\mathrm{i}$ mikropukotina koje su prisutne na akrilatnoj bazalnoj površini zubnih nadoknada, što je mogući uzrok pronađene razlike. Pored korišćene terapije, smanjenju inflamacije palatinalne sluzokože mogli su doprineti poboljšani higijenski režim usne duplje i proteza, kao i noćno nenošenje proteza.

\section{ZAKLJUČAK}

Terapijski ishodi primene antiseptičkog sredstva Listerine $^{\circledast} \mathrm{u}$ lečenju proteznog stomatitisa slični su terapijskim ishodima dobijenim primenom standardne terapije oralnim gelom Daktanol $^{\circledR}$. Oralni antiseptik Listerine ${ }^{\circledast}$ može se koristiti u terapiji proteznog stomatitisa udruženog sa pojavom gljivica iz roda Candida kod nosilaca totalnih akrilatnih proteza. 